\title{
A Bimodal System (Luminophore and Paramagnetic Contrastophore) Derived From Ln(III) Complexes Based on a Bipyridine-Containing Macrocyclic Ligand.
}

Isabelle Nasso, ${ }^{\dagger}$ Chantal Galaup, ${ }^{\dagger}$ Fabien Havas, ${ }^{\dagger}$ Pierre Tisnès, ${ }^{\dagger}$ Claude Picard, ${ }^{*}{ }^{\dagger}$

Sophie Laurent, ${ }^{\ddagger}$ Luce Vander Elst, ${ }^{\ddagger}$ and Robert N. Muller*, ${ }^{*}$

Laboratoire de Synthèse et Physicochimie de Molécules d'Intérêt Biologique, CNRS UMR 5068, Université Paul Sabatier, 118 route de Narbonne, 31062 Toulouse cedex 04, France and Department of Organic and Biomedical Chemistry, NMR and Molecular Imaging Laboratory, University of Mons-Hainaut, B-7000 Mons, Belgium.

\section{Supplementary Material (9 pages)}

* Authors to whom correspondence should be addressed. E-mail: picard@chimie.ups-tlse.fr (C. P.), robert.muller@umh.ac.be (R. N. M.). Phone: (+33) 0561556296 (C. P.), Phone/Fax: (+32) 65373520 (R. N. M.). Fax: (+33) 0561556011 (C. P.).

${ }^{\dagger}$ Université Paul Sabatier.

${ }^{\ddagger}$ University of Mons-Hainaut. 

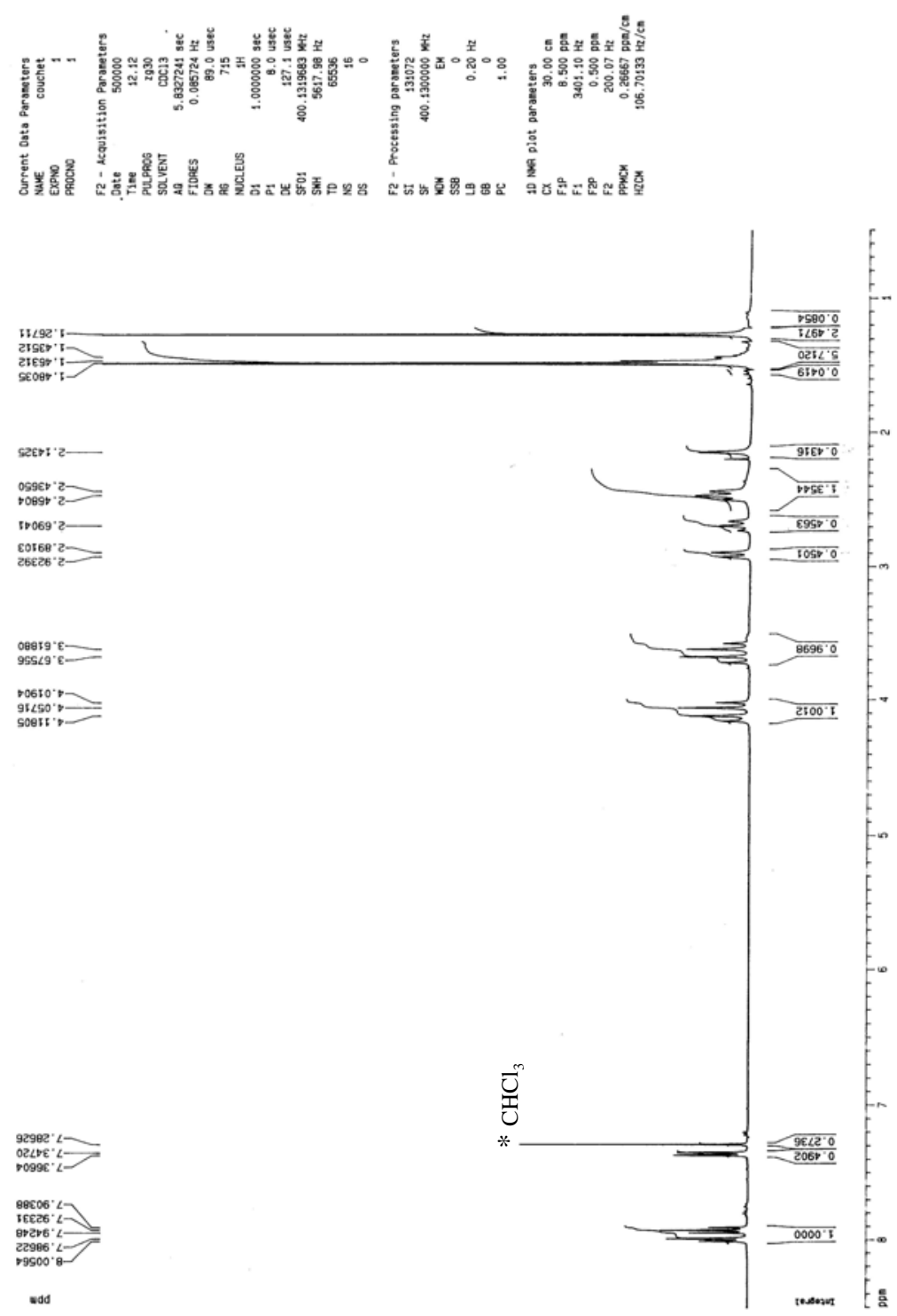

Figure S1. ${ }^{1} \mathrm{H}$ NMR spectrum $\left(\mathrm{CDCL}_{3}, 400 \mathrm{MHz}\right)$ of compound $\mathbf{6} \cdot \mathbf{N a}$. 


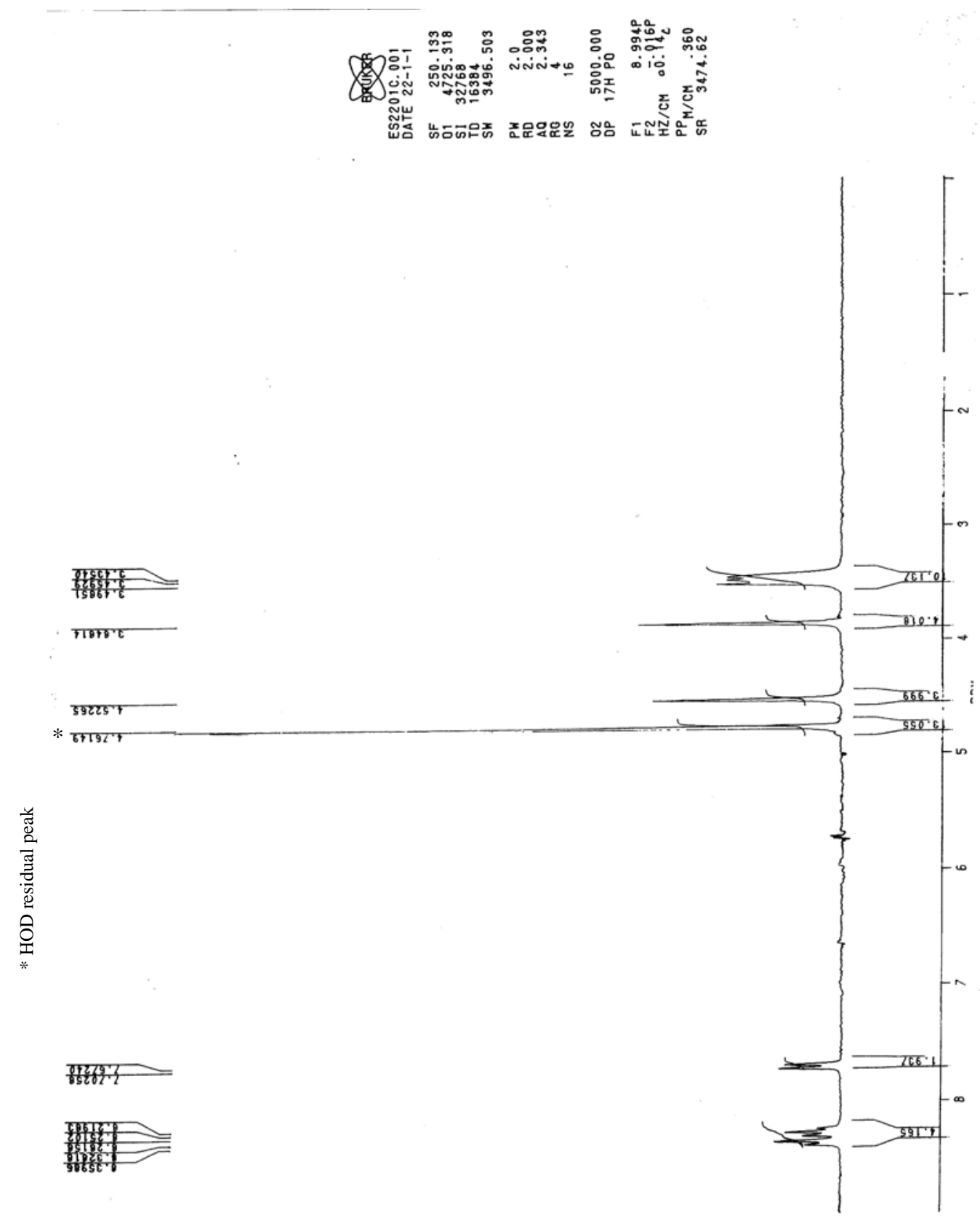

Figure S2. ${ }^{1} \mathrm{H}$ NMR spectrum $\left(\mathrm{D}_{2} \mathrm{O}, 250 \mathrm{MHz}\right)$ of compound $\mathbf{L}^{3} \mathbf{H}_{3}$. 
(a)

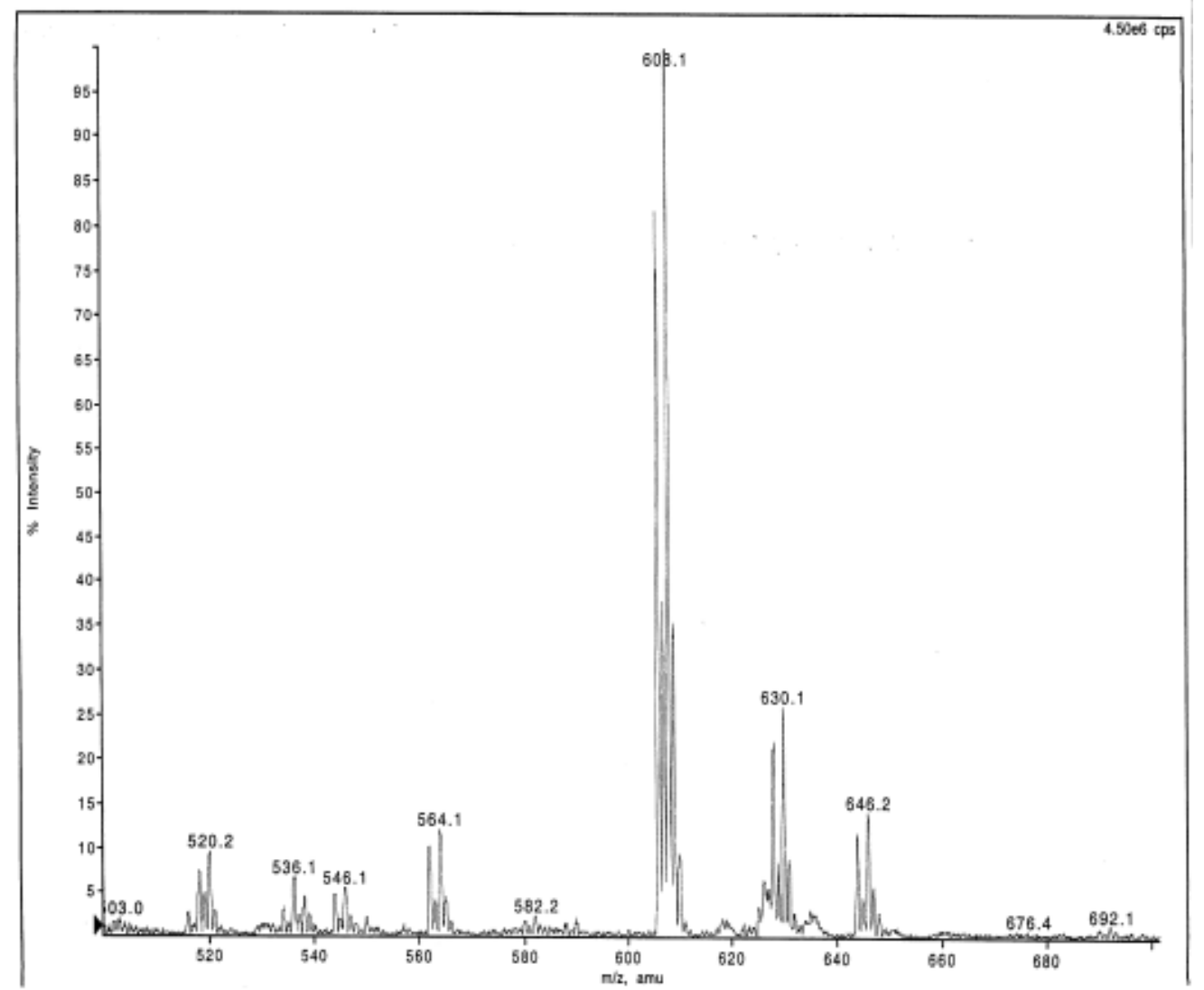

(b)

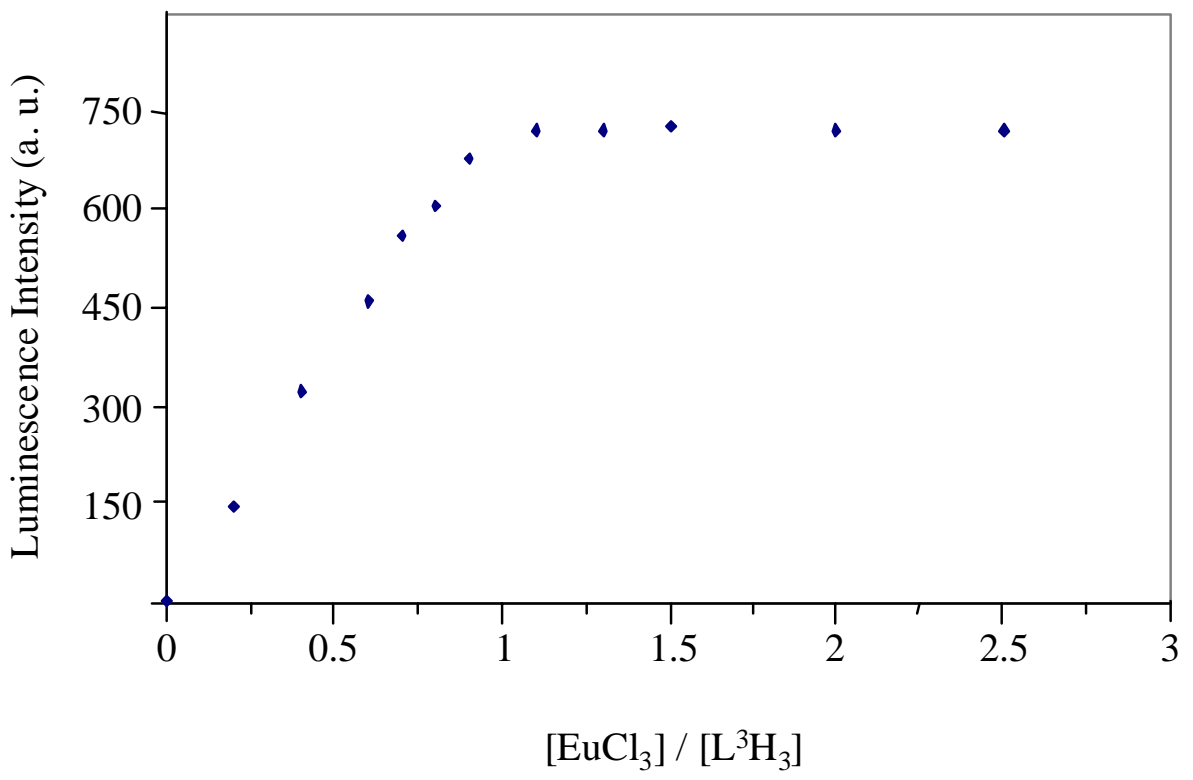

Figure S3. $\mathbf{L}^{3} \cdot \mathbf{E u}$ complex : (a) ESI $^{+}$-MS spectrum obtained by mixing equimolar amounts of $\mathrm{L}^{3} \mathrm{H}_{3}$ and $\mathrm{EuCl}_{3} \cdot 6 \mathrm{H}_{2} \mathrm{O}$ in water, (b) Intensities of the ${ }^{5} \mathrm{D}_{0} \rightarrow{ }^{7} \mathrm{~F}_{2}$ transition peak as the function of $\mathrm{EuCl}_{3} \cdot 6 \mathrm{H}_{2} \mathrm{O}$ added to an aqueous solution of ligand $\mathrm{L}^{3} \mathrm{H}_{3}(10 \mu \mathrm{M})$ in $50 \mathrm{mM}$ HEPES buffer $(\mathrm{pH}=7.3)$. 


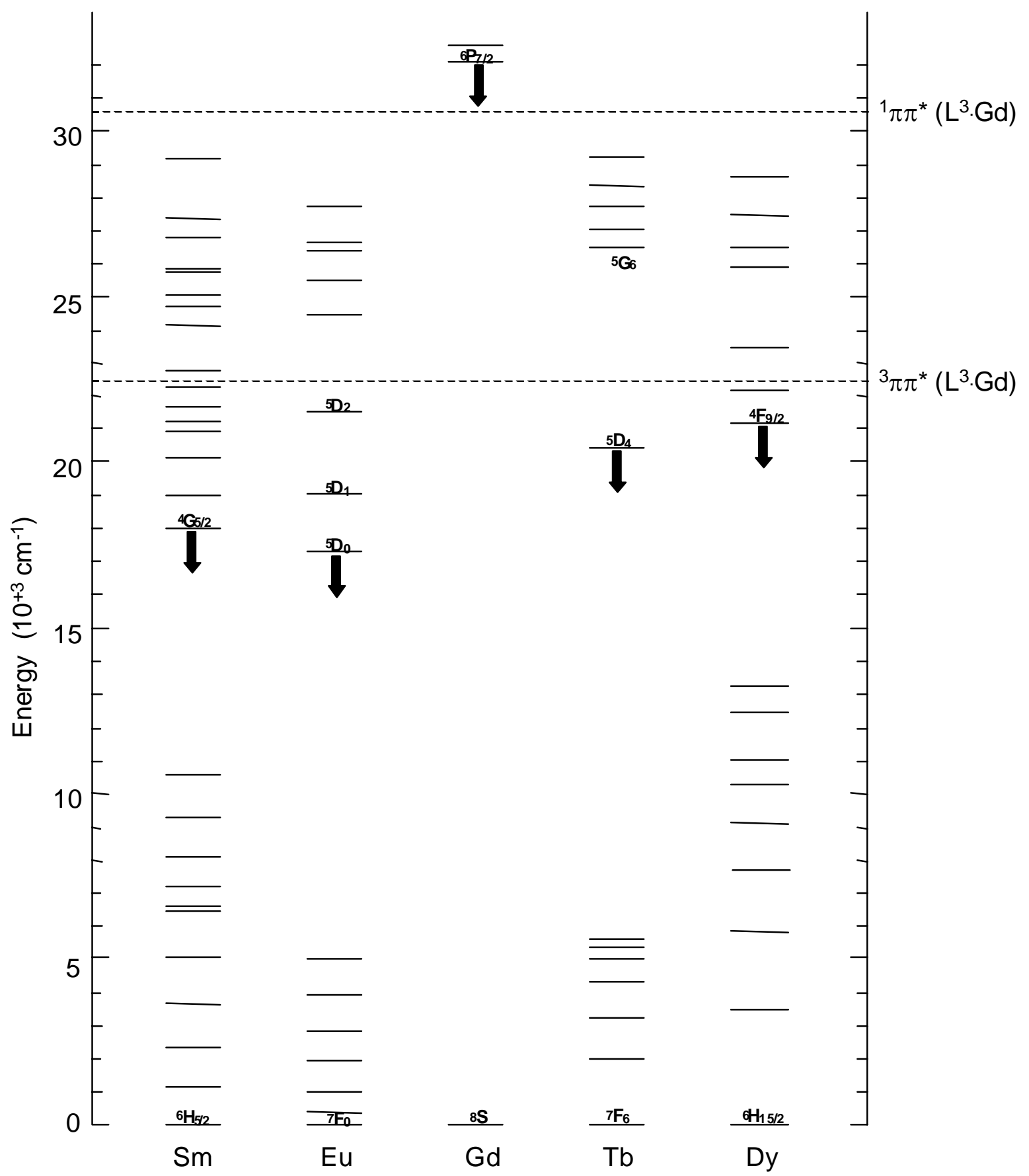

Figure S4. Partial electronic level diagram for $\mathbf{L}^{3} \cdot \mathbf{G d}$ complex and the Sm(III), Eu(III), Gd(III), Tb(III) and Dy(III) ions (from Stein, G.; Würzberg, E. J. Chem. Phys. 1975, 62, 208-213); the arrow represents the lowest luminescent excited state. 


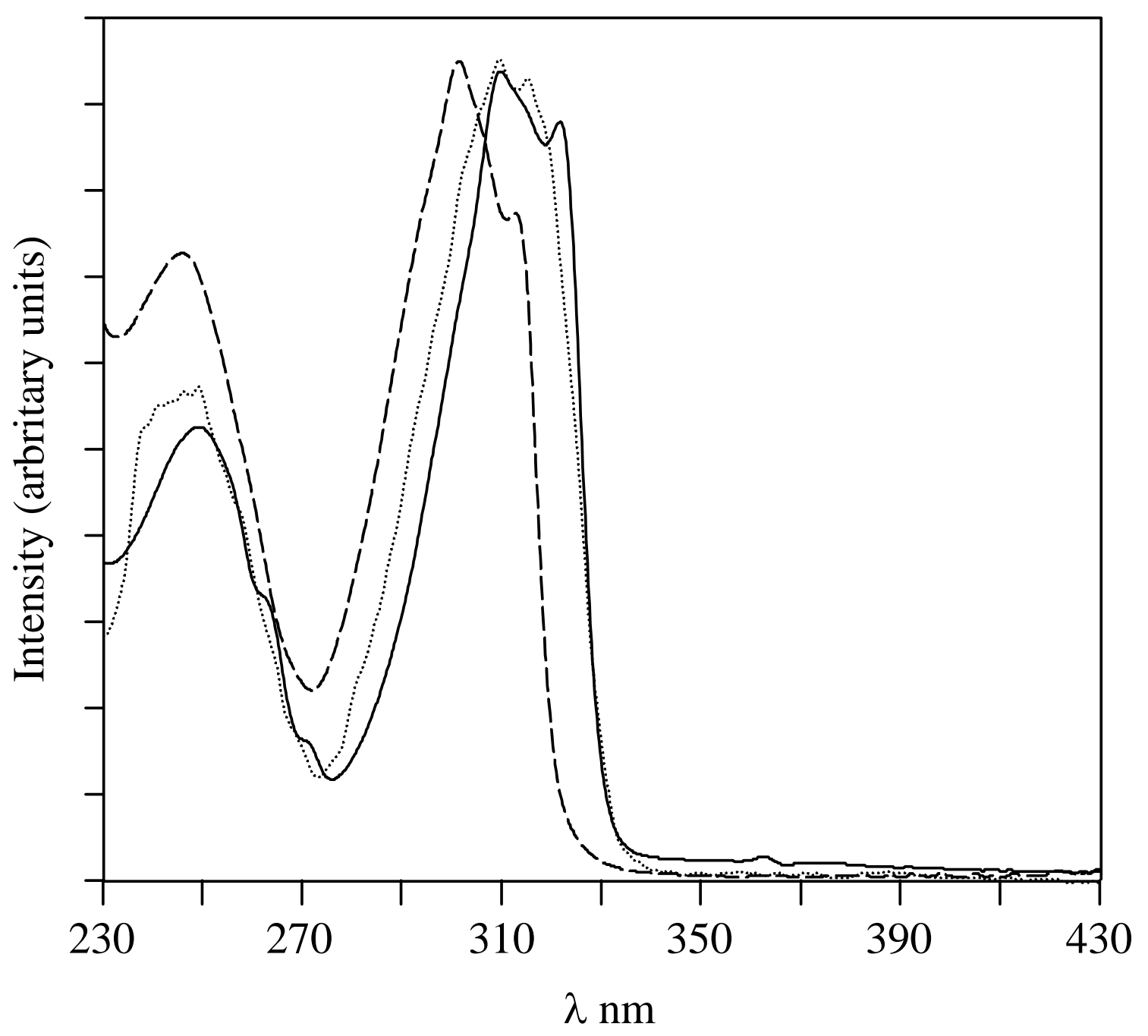

Figure S5. Normalized UV-vis absorption spectra of $\mathbf{L}^{3} \mathbf{H}_{3}$ (dashed line) and $\mathbf{L}^{3} \cdot \mathbf{S m}$ (full line) in HEPES buffer solution ( $\mathrm{pH} 7.3$ ) at 298K. The dotted line represents the excitation spectrum of $\mathbf{L}^{3} \cdot \mathrm{Sm}(\lambda \mathrm{em}=602 \mathrm{~nm})$. 
a)

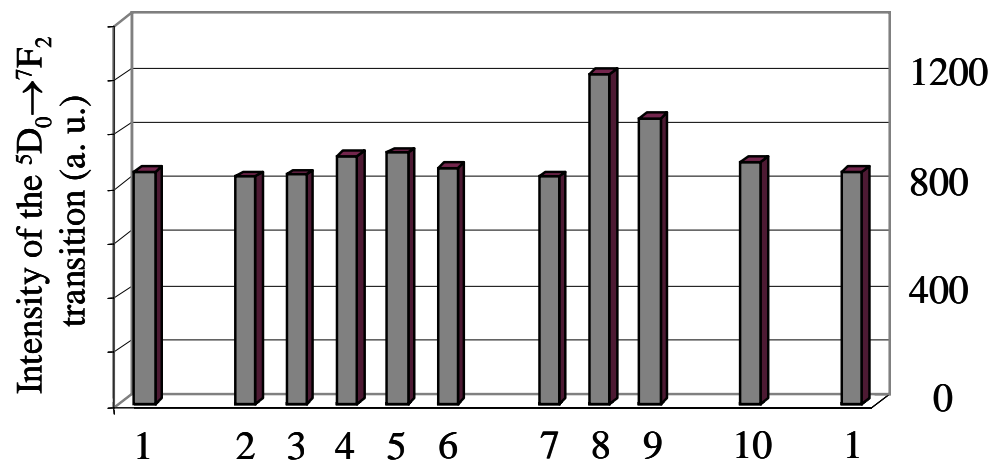

b)

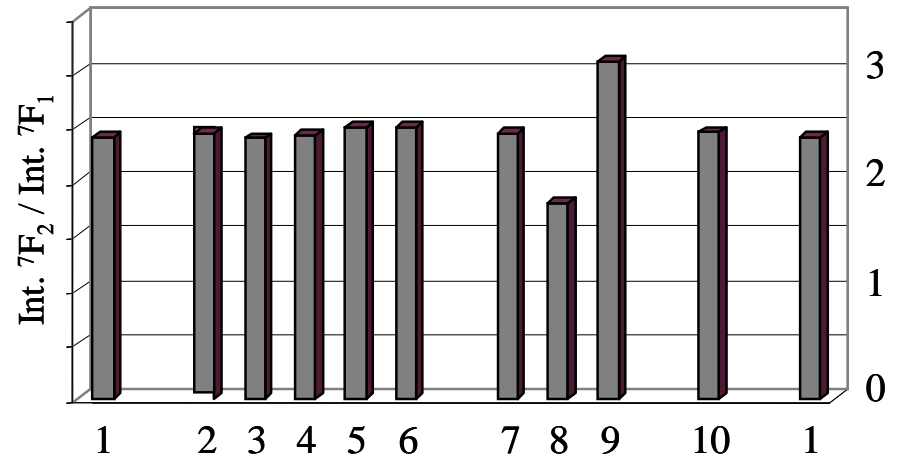

c)

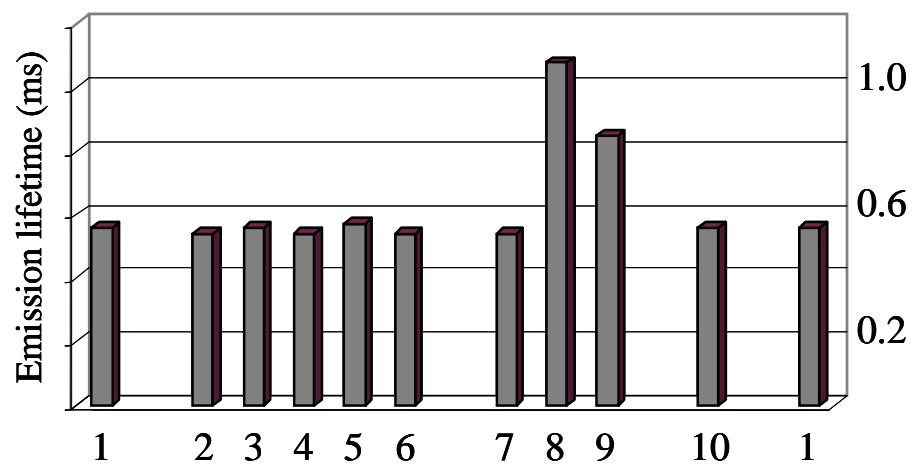

Figure S6. Effects of added cations, anions and BSA on the intensity of the ${ }^{5} \mathrm{D}_{0} \rightarrow{ }^{7} \mathrm{~F}_{2}$ transition (a), the intensity ratio of the ${ }^{5} \mathrm{D}_{0} \rightarrow{ }^{7} \mathrm{~F}_{2}$ and the ${ }^{5} \mathrm{D}_{0} \rightarrow{ }^{7} \mathrm{~F}_{1}$ transition (b), and the emission lifetime (c) in the $\mathbf{L}^{3} \cdot$ Eu complex.

(1) $\left[\mathbf{L}^{3} \cdot \mathbf{E u}\right]=0.01 \mathrm{mM}$ at pH 7.3 (HEPES buffer, $50 \mathrm{mM}$ ), (2) with $\left[\mathrm{Na}^{+}\right]=140 \mathrm{mM}$, (3) with $\left[\mathrm{K}^{+}\right]=5 \mathrm{mM}$, (4) with $\left[\mathrm{Ca}^{2+}\right]=126 \mathrm{mM}$, (5) with $\left[\mathrm{Mg}^{2+}\right]=0.8 \mathrm{mM}$, (6) with $\left[\mathrm{Zn}^{2+}\right]=0.1 \mathrm{mM}$, (7) with $\left[\mathrm{Cl}^{-}\right]=250 \mathrm{mM}$, (8) with $\left[\mathrm{F}^{-}\right]=400 \mathrm{mM}$, (9) with $\left[\mathrm{PO}_{4}{ }^{2-}\right]=50 \mathrm{mM}$, and (10) with [BSA $]=5 \mathrm{mg} / \mathrm{mL}$. 


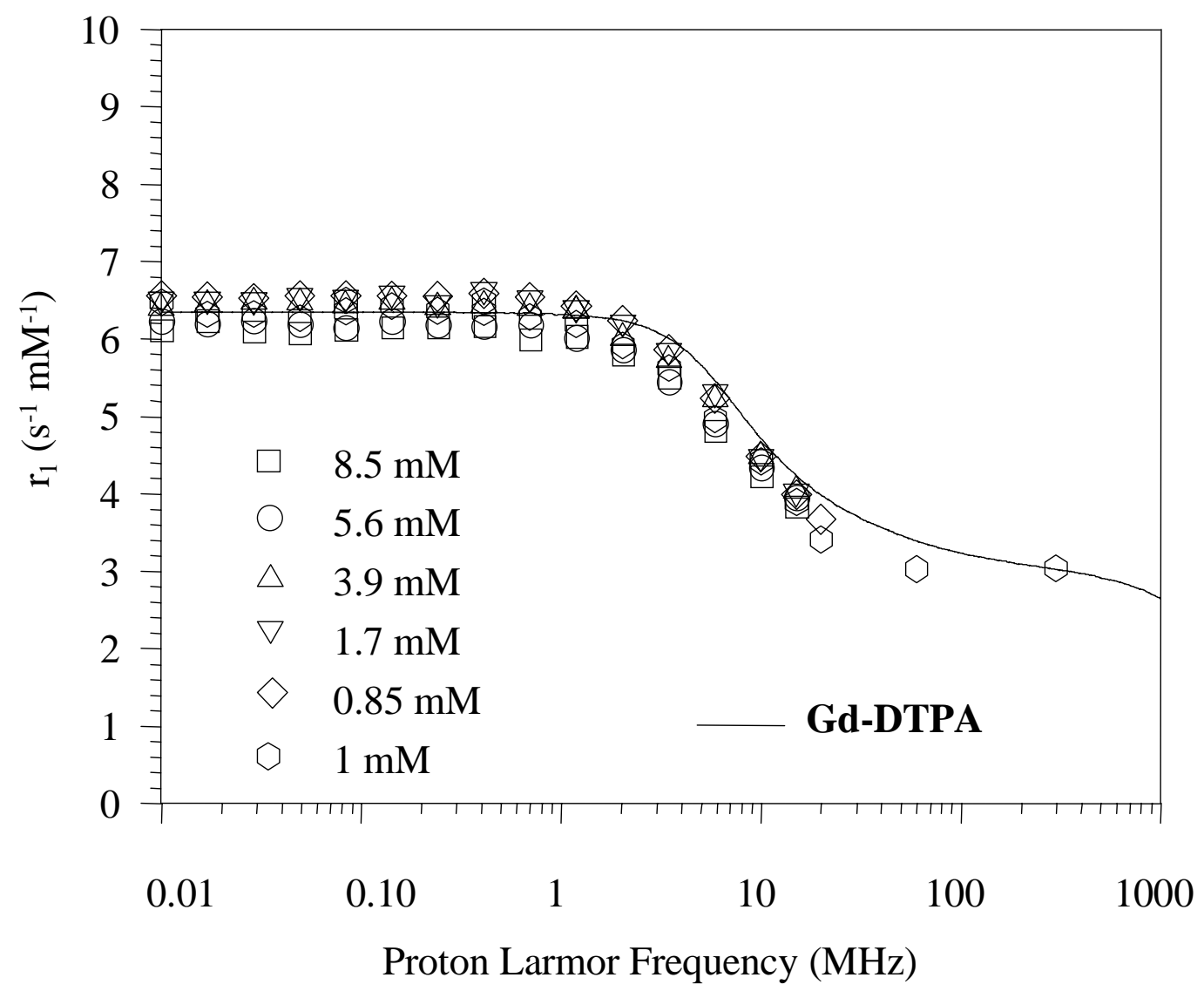

Figure S7. ${ }^{1} \mathrm{H}$ NMRD relaxivity profiles of $\mathbf{L}^{3} \cdot \mathbf{G d}$ complex in water at $310 \mathrm{~K}$ at various concentrations 

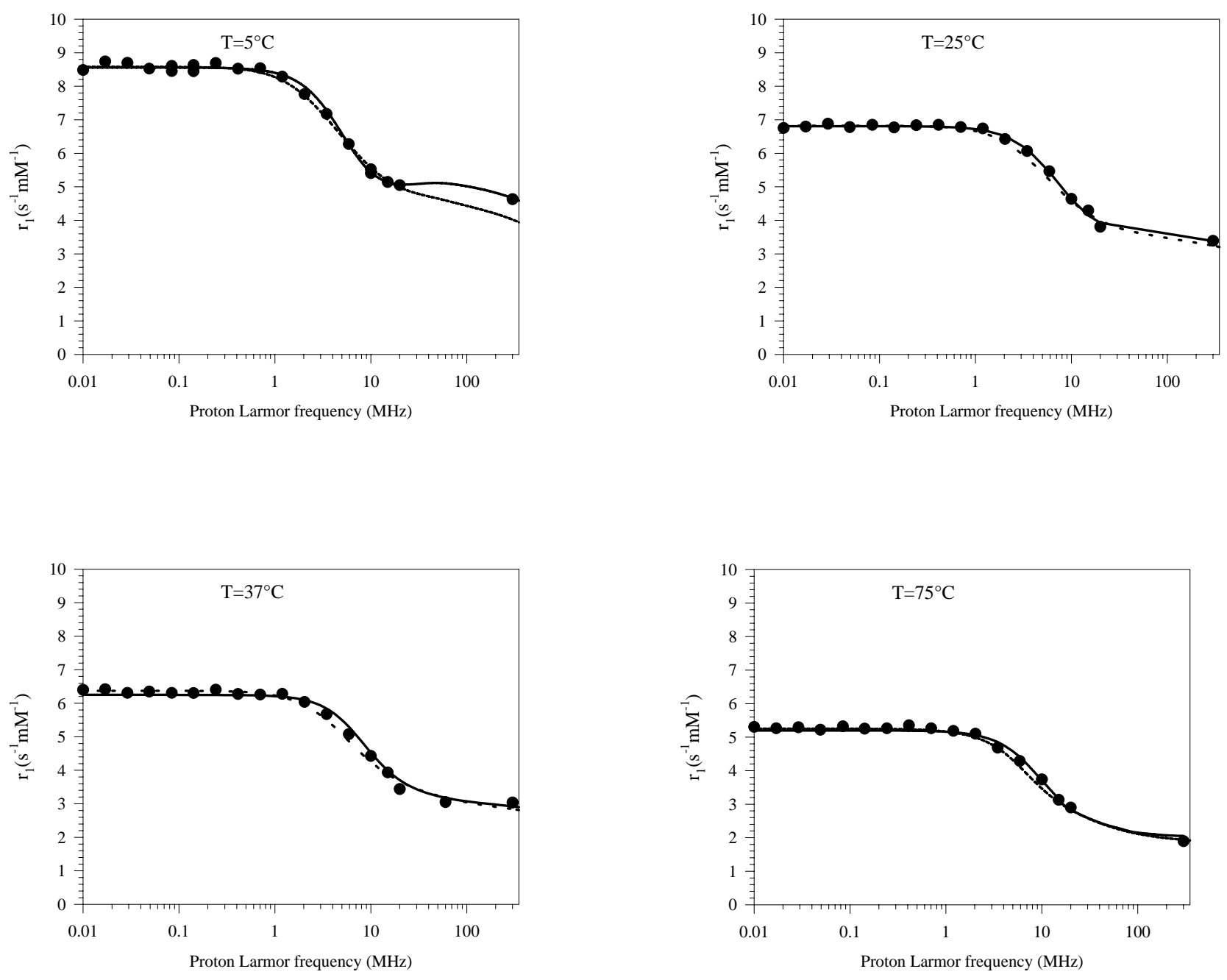

Figure S8. Theoretical fittings of the ${ }^{1} \mathrm{H}$ NMRD relaxivity profiles of $\mathbf{L}^{3} \cdot \mathbf{G d}$ complex in water. The dotted line and the solid line correspond with the first and second types of fittings respectively. 